Comunicações 



\section{Reforming the Global Financial Architecture}

Data e local: 20-24 de junho de 2011, London School of Economics, Londres, Reino Unido

Evento: Reforming the Global Financial Architecture

Representante do BNDES: Pedro Quaresma de Araujo (APE/DEPEQ)

Página eletrônica: <http://www2.1se.ac.uk/study/summerSchools/ executiveSummerSchool/Home.aspx $>$

Entre 20 de junho e $1^{\circ}$ de julho, realizou-se na London School of Economics (LSE), a LSE Executive Summer School 2011. Trata-se de um evento anual realizado pela referida instituição, em que são oferecidos cursos de curta duração sobre determinada temática relacionada à educação executiva. Nesta edição, foram oferecidos os seguintes cursos:

- Applied Valuation and Business Analysis

- Climate Change: Economics and Governance

- Financial Regulation

- Leadership: Current Approaches to Leadership and Applications to Professional Development

- Macroeconomic Challenges of Global Imbalances

- Reforming the Global Financial Architecture

- Strategic Decision Making for Management

- Beyond Rationality: Behavioural Economics and the Modern Economy

- Business in the World Economy

- Corporate Finance and Strategy 
- Investment Analysis

- Macro-econometric Analysis for Practitioners

- Marketing Strategy

- Negotiation and Decision-Making

- The Outsourcing Enterprise: From Cost

- Management to Cloud Services

O curso Reforming the Global Financial Architecture teve como objetivo principal desenvolver uma compreensão da evolução da arquitetura de regulação do sistema monetário e financeiro mundial, sob uma perspectiva multidisciplinar, combinando elementos de ciência política, macroeconomia, finanças e sociologia. Em suma, o curso apresentou elementos para explicar por que o sistema financeiro é tão propenso a crises e qual a possibilidade de reformá-lo depois da mais recente crise financeira internacional. Foram abordados, entre outros temas, os conflitos entre a autonomia nacional e a estabilidade econômica global, as relações político-econômicas entre as instituições financeiras privadas e os governos, os dilemas entre a regulação e a cooperação financeira global, o papel dos novos atores presentes no sistema (fundos soberanos, agências de crédito e hedge funds), o papel do dólar e as moedas rivais, e, finalmente, a governança do próprio sistema financeiro mundial.

A arquitetura monetária e financeira internacional atual vem mostrando constante estresse, mas a sua eficácia e legitimidade nunca foram tão contestadas como agora. Desde a década de 1970, os fluxos financeiros privados vêm superando em muitas vezes, o volume transacionado via comércio internacional. A partir da mais recente crise financeira, tendo em vista os custos sem precedentes para a recuperação do sistema financeiro e a perda de confiança pública que se deu depois da crise, intensificou-se debate sobre os culpados e sobre o que fazer para reformar o sistema.

Segundo a literatura econômica, existem diferentes tipos de crise financeira: crises cambiais, bancárias e de dívida soberana. Crises 
cambiais são marcadas por uma queda acentuada e sustentada no valor de uma moeda, gerando efeitos econômicos negativos como recessão, desemprego, falências bancárias e de empresas, inflação, reduções nos investimentos e perdas em riqueza. Essas crises podem ser provocadas pela ação governamental ou forçada por especuladores privados. São três as condições necessárias para identificar uma crise cambial: (i) queda no valor da moeda; (ii) rápido esgotamento de reservas cambiais; e (iii) a ação do banco central de aumentar as taxas de juros overnight.

Crises bancárias são definidas a partir da identificação de insolvência no sistema bancário, que ocorre quando os valores dos ativos estão aquém dos passivos. Em outras palavras, quando há uma alta proporção de empréstimos inadimplentes em relação aos ativos. A identificação das crises bancárias é baseada em uma ou mais das quatro seguintes medidas aceitas: (i) relação dos ativos inadimplentes no sistema bancário superior a 10\%; (ii) o custo de uma operação de resgate de pelo menos 2\% do PIB; (iii) a nacionalização de bancos de grande escala; e, (iv) corridas bancárias ou outras medidas de emergência decretadas pelo governo.

Crises de dívida soberana e de inflação seguem-se a crises bancárias e cambiais. Crises de dívida soberana ocorrem quando um governo nacional é incapaz de pagar juros ou capital de suas dívidas com estrangeiros ou credores privados em razão da falta de reservas cambiais. Essas crises são semelhantes à insolvência de bancos privados, resultando muitas vezes em crises cambiais, porque a escassez de reservas de divisas, além de gerar fuga de capitais, reduz a capacidade de se manter uma taxa de câmbio fixa.

Desde o início da década de 1980, as crises tornaram-se mais frequentes, se comparadas com aquelas do pós-guerra (crises financeiras costumavam acontecer com relativa regularidade até os anos 1940). Teorias econômicas e de economia política podem nos ajudar a entender o porquê. De acordo com o pensamento econômico, a abertura das contas de capital teve um papel importante, ao facilitar a fuga de 
capitais. A estreita relação entre a liberalização da conta de capital e a ocorrência de crises bancárias confirmam essas interpretações. Nos últimos 25 anos, o setor financeiro tem recebido um tratamento favorecido em razão de seu enorme peso político, não visto desde o início do século XX, possibilitando um quadro regulamentar que beneficiou o próprio setor antes da crise e permitiu repassar aos governos todos os problemas substanciais, além de bloquear reformas essenciais nos resultados de regulamentação no pós-crise. De acordo com a economia política, sabe-se que a frequência das crises se baseia no crescente poder político e ideológico do setor financeiro. Em outras palavras, esse setor da economia tornou-se a "nova oligarquia", influenciando as políticas de regulação, especialmente as políticas de desregulamentação financeira.

$\mathrm{Na}$ verdade, a complacência política é apontada como um dos principais determinantes que impulsionam as transações financeiras para altos níveis de alavancagem, favorecendo o aumento do porte e a importância sistêmica de algumas instituições financeiras no pré-crise. Como essas instituições estavam aumentando seus ativos, elas poderiam arrecadar fundos a custos cada vez mais baixos, uma vez que foram consideradas financeiramente saudáveis por parte dos credores do banco. Dessa maneira, elas tendem a correr muitos riscos em tempos estáveis, mas no caso de uma crise sistêmica, seriam tidas "grandes demais para falir" sendo, portanto, beneficiadas por programas de resgate com recursos públicos.

Os principais mecanismos pelos quais o setor financeiro influencia os resultados das políticas públicas são gerados a partir de "restrições estruturais" e de captura política. Abertura da conta de capital é a principal causadora da "restrição estrutural", pois implica uma escolha limitada, para os países dependentes, entre fixação de taxa de câmbio e autonomia de política monetária. Captura política ocorre quando os atores privados influenciam os resultados das políticas para obter vantagens sobre outros atores ou sobre a própria sociedade. Essa 
captura pode ser favorecida por lobbies, financiamentos de campanha e também pelo livre trânsito entre o setor público e o privado. Entre 1998 e 2010, o setor financeiro foi o que mais se destacou nos lobbies oficiais, a crescente divergência entre as plataformas dos partidos e as preferências políticas do eleitorado demonstra o impacto maior de financiamento eleitoral em debates políticos. Finalmente, temos o fluxo de pessoas e conexões pessoais entre Wall Street e Washington, que permite facilmente o acesso do setor financeiro aos funcionários do governo. Outros fatores que aumentam o poder do setor financeiro estão na captura intelectual, que confere legitimidade acadêmica para as políticas de desregulamentação.

Para entender a tolerância dos banqueiros centrais dos governos e dos banqueiros centrais em relação às práticas do sistema financeiro, não se pode deixar de considerar a relação entre a desregulamentação financeira e o estímulo à expansão do consumo. Recentemente, a expansão do crédito (especialmente associada com hipotecas) compensou a estagnação dos salários reais nos países desenvolvidos. Da mesma maneira, a política monetária expansionista de juros baixos desempenhou um papel importante para contrabalançar as pressões políticas do crescimento econômico sem geração de empregos ao longo dos anos 2000.

Em relação ao BNDES, o evento contribuiu para aprimorar a análise e a identificação de temáticas de pesquisa relacionadas aos desdobramentos da crise financeira internacional, além de estreitar os laços institucionais com a London School of Economics (LSE). As informações oferecidas no curso também são de grande valia para o acompanhamento da regulação financeira internacional, subsidiando a atuação do BNDES nos fóruns internacionais sobre a temática. 
